\title{
Parenting and child adjustment: a comparison of Turkish and English families
}

\section{Berna Aytac, Alison Pike \& Rod Bond}

To cite this article: Berna Aytac, Alison Pike \& Rod Bond (2019) Parenting and child adjustment: a comparison of Turkish and English families, Journal of Family Studies, 25:3, 267-286, DOI: 10.1080/13229400.2016.1248855

To link to this article: https://doi.org/10.1080/13229400.2016.1248855

曲 Published online: 20 Nov 2016.

Submit your article to this journal $\asymp$

Џll Article views: 288

Q View related articles $\sqsubset$

View Crossmark data

4 Citing articles: 1 View citing articles 


\title{
Parenting and child adjustment: a comparison of Turkish and English families
}

\author{
Berna Aytac ${ }^{a}$, Alison Pike ${ }^{b}{ }^{b}$ and Rod Bond ${ }^{b}$ \\ ${ }^{\mathrm{a}}$ Faculty of Letters, Department of Psychology, Hacettepe University, Ankara, Turkey; ${ }^{\mathrm{b}}$ Department of \\ Psychology, University of Sussex, Brighton, UK
}

\begin{abstract}
The links between parenting and child behaviour in cultural context have received increasing research attention. We investigated the effect of parenting on child adjustment using a multi-method design, comparing English and Turkish families. The socioeconomically diverse samples included 118 English and 100 Turkish families, each with two children aged 4-8 years. Mothers completed questionnaires as well as parent-child interaction being assessed using a structured Etch-a-Sketch task with each child separately. Children were interviewed about their relationships with their mothers using the Berkeley Puppet Interview. Multiple-group Confirmatory Analysis was used to test Measurement Invariance across groups, and a multi-informant approach was used to assess parenting. We found partial crosscultural measurement invariance for parenting and child adjustment. Strikingly, the association between parenting and child adjustment was stronger among English families than Turkish families. Culturally distinct meanings of both parenting and child behaviour must be considered when interpreting their association.
\end{abstract}

\section{ARTICLE HISTORY}

Received 14 October 2015

Revised 26 September 2016

Accepted 11 October 2016

\section{KEYWORDS}

Parent-child relations; crosscultural; adjustment problems; measurement invariance

Parenting-child behaviour links in cultural context have received increasing research attention (Chen et al., 1998; Deater-Deckard \& Dodge, 1997; Ho, Bluestein, \& Jenkins, 2008; Kotchick \& Forehand, 2002). The current study adds to this literature by comparing two target children from English and Turkish families using a multi-informant design. To put the research in context, a focused review of culture, children's adjustment in relation to parenting, and their links with culture follows. The cross-cultural challenge of equivalence in measurement is also considered.

\section{Culture}

Culture is a socially interactive process of construction consisting of shared activities, meanings, beliefs, symbols, norms, and values (Greenfield, Keller, Fuligni, \& Maynard, 2003; Schwartz, 2006), and human development always occurs within culture (Kagitcibasi, 2007; Oyserman, 2011). Kagitcibasi (2007) states that cultural context provides specific 
meanings to observed behaviours that can explain the dynamics of the changing behaviours; the same behaviour might have different meanings in different cultures. Likewise, conceptions of parenting change depending on cultural models (Keller et al., 2006). The research presented here was driven by the motivation to investigate the relation between mother-child relationship quality and child adjustment across cultures along with investigating measurement invariance.

As argued by Harkness and Super (2006), comparative cross-cultural studies should be implemented to distinguish the patterns and parenting practices that are universal and culture-specific. These may not be revealed in a mono-cultural study. Therefore, in order to have a better understanding of the relation between parenting and child adjustment, studying the role of culture and its consequences becomes imperative.

Eco-cultural models, a combination of cultural and ecological elements within and across settings, state that humans are multiple-level beings (i.e. inner-biological, individualpsychological, dyadic, social network, community, societal, cultural, outer physicalecological, and historical), and there is a dynamic interaction among these levels (Bronfenbrenner, 1979; Erez \& Gati, 2004; Kagitcibasi, 2007; Lerner \& Lerner, 1987; Super \& Harkness, 1986). A common conceptual strength of these eco-cultural models is not only the inclusion of multiple levels of analysis but also the systematic attention to the relationships among them. These models framed the dynamics between individuals and culture in objective, structural, affective, and behavioural terms (Worthman, 2010).

One of these eco-cultural models, Bronfenbrenner's Ecological Systems Theory (1979) defines the environment as a set of nested structures, each inside the next, and posits that there are different types of systems that affect individuals. The innermost level is the microsystem including children's relationships and interactions with their immediate surroundings, for example, the family and home context. The macrosystem, outermost level, includes cultural values, customs, laws, and resources. Cultural values shape and determine the immediate contexts experienced by children, the short- and long-term goals parents hold for their children, and the practices parents employ in attempting to meet these goals (Bornstein \& Cheah, 2006). In our paper, the mother-child relationship was investigated as the microsystem and culture as the macrosystem by comparing English and Turkish families. This allowed us to assess culture's overarching role in shaping the ecology of parenting and child adjustment.

\section{Parenting in cultural context}

Although parents with different cultural backgrounds may display similar behaviours, parenting is influenced by the values and norms of a specific culture (Dwairy, 2010) and the meaning of parenting practices is dependent on culture (Chan, Penner, Mah, \& Johnston, 2010; Deater-Deckard, Dodge, Bates, \& Pettit, 1996). These variations in parenting between cultures can stem from the different needs of societies, and are probably contextually functional (Ogbu, 1981).

Considerable research has focused on comparing the parenting practices of ethnic minority and majority groups. Factors that affect parenting are generally inferred from studies that compare minority groups with the majority. For example, several researchers have reported ethnic group differences in the use of physical punishment. Specifically, harsh discipline is more strongly linked to child aggression among 
European Americans than among African Americans (Deater-Deckard \& Dodge, 1997; Lansford, 2010). This pattern - strongest links for European origin children - also emerged from a population-based sample of Canadian families (Ho et al., 2008). This robust finding does not hold true for all cultural comparisons, however. For example, in a study of Anglo and Indian families living in England, parenting-child behaviour links were similar across the two groups (Atzaba-Poria, Pike, \& Deater-Deckard, 2004). Likewise, no moderation by culture was found by Rowe et al. (1994). Given these contradictory findings and lack of previous research in Turkey, the main aim of the current study was exploratory in nature.

In comparison to minority ethnic group research, less research has compared parenting across cultures. Extant findings have demonstrated, however, that individualistic and collectivistic cultures differ in their parenting behaviours. Phalet and Schonpflug (2001) found that parents in collectivistic countries (e.g. Turkey, Singapore) tend to stress conformity goals such as obedience and respect, whereas parents in individualistic countries (e.g. Germany, the United States) stress autonomy goals such as agency and independent thinking. Relationships between parents and their children in collectivistic societies are also closer and more mutually dependent than in individualistic societies (Dwairy, 2010).

The current study considers two countries, Turkey and England, in order to make cross-cultural comparisons. In England, an individualistic culture, autonomy, self-sufficiency, and independence have emerged as important values that guide parenting (Rothbaum, Pott, Azuma, Miyake, \& Weisz, 2000). On the other hand, patriotism, respect for authority, differentiation between girls and boys, and high valuing of sons are among the cultural features of traditional Turkish families (Kagitcibasi, 2007). However, as Tamis-LeMonda et al. (2008) point out, globalization and technology have changed many traditional collectivist societies, including Turkey. As a result, highly educated and urbanized Turkish mothers do not expect their children to be as obedient as did their mothers and grandmothers, but they still expect their children to maintain close family ties when they grow up (Ataca, 2009; Imamoglu, 1998).

\section{Parenting and children's adjustment}

A major goal of socialization is guiding children towards appropriate behaviour and away from socially unacceptable or destructive behaviour. These problem behaviours are key risk factors for subsequent juvenile delinquent behaviour, unemployment, poor social relationships, and adult crime (Fraser, 1996; Loeber, 1990; Slobodskaya, 2015).

Parental warmth, support, monitoring, and responsiveness are associated with fewer child adjustment problems (Caspi et al., 2004; Mäntymaa et al., 2009; Rothbaum \& Weisz, 1994; Slobodskaya, 2015), whereas harsh physical discipline, hostility, and rejection are associated with more problematic behaviours (Choe, Olson, \& Sameroff, 2013; Slobodskaya, 2015; Stormshak, Bierman, McMahon, \& Lengua, 2000). As reviewed by Campbell (1995), child compliance is associated with higher warmth, appropriate limit setting, and the use of explanations and reasoning; on the other hand, arbitrary, inconsistent, negative, or uninvolved maternal behaviour is associated with noncompliance and defiance. Also, punitive discipline is associated with internalizing behaviours (Stormshak et al., 2000). 


\section{Links with culture}

Children with different socialization experiences can grow into adults who function competently in their respective cultures (LeVine, 1988), and parents are crucial transmitters of cultural values (Kagitcibasi, 2007; Rogoff, 1990). For example, the meaning that a child attaches to a specific parenting behaviour (e.g. hugging, yelling) can vary between cultures. Deater-Deckard and Dodge (1997) suggest that in cultures where physical punishment is a predominant and normative form of discipline, harsh discipline might be seen as acceptable, but in the cultures where it is forbidden or discouraged, it is considered poor parenting. If children perceive their parents' disciplinary messages as being unfair or unreasonable, they may show worse long-term adjustment (Lansford, 2010). Thus, the effect of the parenting behaviours may depend on the context in which it is used.

Although no previous research has compared children's behaviour in England versus Turkey, as reviewed by Chen and French (2008), children living in cultures where obligation, group harmony, and family interdependence are valued display fewer externalizing problems than those children living in cultures where competitiveness and the pursuit of personal goals are valued. Similarly, individualistic cultures seem to allow more coercive and aggressive behaviours, whereas collectivistic cultures tend to inhibit aggressive behaviours. For example, aggressive, disruptive, and defiant behaviours are prohibited in China because of their potential threat to group harmony.

\section{Measurement invariance}

The equivalence of assessment tools is a salient issue in cross-cultural research. In general, the same tools are used for samples from different cultures - the assumption being that these tools are equally valid across cultures. However, cultural differences mean that the same questions may have different meanings for people from different cultures (Kankaras \& Moors, 2010). It is a crucial prerequisite that constructs being measured have the same theoretical structure for all groups in a study (Johnson, 2006). This is why a method, measurement invariance, has been developed to investigate whether an instrument operates in the same way in different groups or cultures. Multiple-group Confirmatory Factor Analysis (MGCFA) appears to be the mostly used approach in the study of measurement invariance across different groups (Byrne, Shavelson, \& Muthen, 1989; Comsa, 2010). Also, MGCFA became an appealing approach to examine whether items and the factorial structure of a measurement instrument were equivalent across different groups with the increased interest in cross-cultural psychology (Johnson, 2006).

There are studies that employ measurement invariance method for within- or between cultural comparisons. For example, Huang et al. (2011) examined the measurement invariance of parental discipline strategies in nine countries, and concluded lack of measurement invariance. Adamsons and Buehler (2007) examined measurement invariance for parenting constructs (acceptance, intrusiveness, and harshness) across mothers and fathers; whereas Luk, King, McCarty, Vander Stoep, and McCauley (2016) for parenting constructs (perceived parental warmth, psychological control, and knowledge) across European and American adolescents. Adamsons and Buehler (2007) found measurement invariance for intrusiveness and harshness across mothers and fathers, and Luk et al. 
(2016) found weak factorial invariance (also called metric invariance) of both mother and father parenting across cultures, indicating a cross-cultural similarity in the interpretation of these parenting dimensions. Similarly, Gomez and Rohner (2011) used measurement invariance method to examine the factor structure of Parental Acceptance-Rejection Questionnaire between Australian and American adults. They found equivalence for all items for the mother and equivalence for 54 of the 60 items for the father. To date, no existing measurement invariance study that we are aware has examined the link between parenting and child adjustment between Turkey and England.

\section{Current study}

The present study contributes to the parenting-child behaviour literature by comparing Turkish and English families living in their native countries. We also used maternal questionnaires, child interviews, and videotaped parent-child interactions to gain a more complete picture of mother-child relationship quality.

Measurement invariance was chosen as the method to test the equivalence of constructs between England and Turkey. Also, the replicability of our findings is tested by including two children per family. The implicit assumption made is that parenting and its effects are similar across all children within families (Dunn \& Plomin, 1990). When researchers assess family effects using one child per family, necessary attention may not be given to within-family variability. Testing for invariance between older and younger siblings within families also provides a means for improving our models' robustness.

With the use of siblings as an internal replication, we used structural equation modelling to address the following questions: (1) Is the measurement of mother-child relationship quality (observed positivity, observed negativity, child-rated positivity, child-rated negativity, mother-rated positivity, and mother-rated negativity) similar or different between England and Turkey? (2) Is the measurement of children's behaviour problems (hyperactivity, conduct problems, emotional problems, and peer problems) similar or different between England and Turkey? (3) Is the link between mother-child relationships and children's behaviour similar or different between England and Turkey?

\section{Method}

\section{Participants}

The current study uses data from the 118 two-parent families that participated in the Sisters and Brothers Study between 2002 and 2003 (see Pike, Coldwell, \& Dunn, 2006). All families had two target children aged $4-8$ years. The average age of the older siblings was 7.4 years ( $S D=9.47$ months), and younger siblings 5.2 years ( $S D=7.20$ months). The older siblings were not necessarily the oldest, and the younger siblings were not necessarily the youngest in their families. Analogous data were collected from 100 Turkish families in 2010. The average age of the older siblings was 8.1 years ( $S D=9.88$ months), and the average age of the younger sibling was 4.7 years $(S D=9.41$ months). There were significant differences between the older siblings' ages $(t=6.21, p<.05)$ and the younger siblings' ages $(t=-5.49, p<.05)$ across cultures. Current study investigates sibling pairs in early to middle childhood. Most of children's exchanges with others during early childhood occur 
in their families and their social networks expand significantly during middle childhood. By the ages 10-12 years, children become more involved in peer relations (Collins, Madsen, \& Susman-Stillman, 2005). The older siblings in the sample were not yet 9 years old. This aims to capture family relationships still characterized by high intensity and emotionality, before the pulls from outside the family that can serve to weaken the warmth and intimacy of the bonds had taken hold (Dunn, 2002).

Both samples comprised ordinary families drawn from the local community rather than families facing particular difficulties. Families came from a mix of working-class and middle-class backgrounds, and there was a wide range of educational attainment among the families. There was a significant association between culture and education for both mothers $\left(\chi^{2}(5)=45.75, p<.05\right)$ and fathers $\left(\chi^{2}(5)=95.96, p<.05\right)$, indicating that the Turkish mothers and fathers were more highly educated. Forty-four per cent of English mothers and $50 \%$ of English fathers had left school by age 16, in comparison to $30 \%$ and $16 \%$ of Turkish mothers and fathers, respectively. The association between working situation and culture was significant for mothers $\left(\chi^{2}(3)=105.53, p<.05\right)$ but not for fathers $\left(\chi^{2}(2)=1.15, p=.56\right)$; the Turkish mothers were far less likely to be in paid employment than were their English counterparts.

\section{Recruitment and procedure}

This study has been approved by the ethics committee at University of Sussex. Families in England were recruited through information leaflets distributed to parents of children aged 4-6 via schools in the Sussex area. Turkish families were recruited through information leaflets distributed to parents at nursery and primary schools, as well as via online family websites, mailing groups, and recommendations made by families participating in the study in Central Anatolia area. We acknowledge that each sample is only representative of part of the country under study. One or two researchers conducted home visits which began by gaining informed consent by mothers. These visits lasted 1.5-2 hours. Mothers and children were interviewed separately and mothers completed questionnaires. Also, mothers and each child in turn were videotaped while completing a structured task. The Etch-a-Sketch drawing toy that has two dials, one for drawing vertically and the other for drawing horizontally. The mother and child were each assigned a dial, and told not to touch each other's dial, so that they had to cooperate to complete the task. They were first asked to copy a rectangle with a cross through it, and then a more complex drawing of a house. Families in both countries have been given a CD that recorded their interactions.

\section{Measures}

Questionnaires were translated into Turkish by two researchers independently, one of whom was the first author; they then met to agree on the translation. This was then back-translated into English by a third translator. The first author revised the translation once again, and piloted the questionnaires with five mothers to check for clarity. This resulted in a few additional minor modifications to the final Turkish version of materials.

Strengths and Difficulties Questionnaire (SDQ; Goodman, 1997). Mothers were asked to rate the strengths and difficulties of their children based on a 3-point scale ranging from 1 
(not true) to 3 (certainly true). The four scales used were: Hyperactivity (5 items: e.g. "restless, overactive, cannot stay still for long"); Emotional Symptoms (5 items: e.g. "many worries, often seems worried"); Conduct Problems (5 items: e.g. "often fights with other children or bullies them"); and Peer Problems (5 items e.g. "rather solitary, tends to play alone"). Cronbach's alphas ranged from .76 to .82, for older and younger siblings, in Turkey and England.

Parent-Child Relationship Scale (Hetherington \& Clingempeel, 1992). Mothers were asked to rate 15 items about aspects of their relationship with their children, for example, "How much do you enjoy spending time alone with your child?" and "How much do you criticise your child?" on a 5-point scale, ranging from 1 (not at all) to 5 (extremely). Two subscales are derived from this measure: Parent-Child Positive Relation (for Turkey, Cronbach's alphas $=.77$ and .69 for older and younger siblings, respectively; for England, Cronbach's alphas $=.65$ and .64 for older and younger siblings, respectively), and Parent-Child Negative Relation (for Turkey, Cronbach's alphas $=.80$ and .81 for older and younger siblings, respectively; for England, Cronbach's alphas $=.68$ and .79 for older and younger siblings, respectively).

Berkeley Puppet Interview (BPI) (Ablow \& Measelle, 1993). This 12-item interview aims to obtain reports from young children about their relationship with their mothers. During the audio-taped interview, two identical puppets make opposing statements about their mothers (e.g. 'My mum is nice to me' and 'my Mum is not nice to me') and then ask the child about themselves (e.g. 'How about your mum?'). The researcher covers her face with the puppets in order to encourage the child to interact directly with the puppets. Two scales assess children's relationships with their mothers; one is warmth and enjoyment ("My mum hugs and kisses me", "Me and my mum have fun together") and the other is anger and hostility ("My mum is mean to me", "My mum shouts at me when she is cross"). When a child chooses a response option as expressed by the puppet, a code 2 (for a negative response - "My mum is not nice to me") or a code 6 (for a positive response - "My mum is nice to me too") is used. When a child amplifies a statement (e.g. "My mum is horrible to me" or "My mum is really nice to me"), a code 1 (negative) or 7 (positive) is used. A code 3 or 5 indicates a response that is qualified in some way (e.g. "My mum isn't nice to me most of the time" or "My mum is nice to me most of the time"). Finally, a code 4 is used when a child indicates that both response options apply to them. For Turkey, internal consistencies for the BPI subscales range from .53 to .54 for the older siblings and .66 to .68 for the younger siblings. For England, internal consistencies for the BPI subscales range from .66 to .83 for the older children and .60 to .68 for the younger children.

Etch-a-Sketch coding (Deater-Deckard, 2000). The mother and each child in turn were videotaped using an Etch-a-Sketch drawing toy that has two dials, one for drawing vertically and the other for drawing horizontally. The mother and child were each assigned a dial, and told not to touch each other's dial, so that they had to cooperate to complete the task. They were first asked to copy a rectangle with a cross through it, and then a more complex drawing of a house. Ratings of each mother-child dyad from the videotaped interactions were made by the first author using the Parent-Child Interaction System or PARCHISY (Deater-Deckard, 2000; Deater-Deckard, Pylas, \& Petrill, 1997). Observers completed two 7-point Likert-type scales ( $1=$ none, $7=$ exclusive use of/constantly) from the PARCHISY: positive affect (i.e. smiling, laughing, and enjoyment of the task) 
and negative affect (i.e. rejection, frowning, and cold/harsh voice). In order to test reliability of observations, a second researcher coded independently the $40 \%$ of the videos. Significant correlations have been found for positive affect $(r=70, r=.69)$ and negative affect $(r=.84, r=1.00)$; for Turkey and England, respectively.

\section{Plan of analysis}

Analyses were carried out using AMOS Structural Equation Modeling 16 (Arbuckle, 2007). The analyses included three models: a measurement model for parenting, a measurement model for problem behaviour, and a structural model. These were multigroup analyses comparing Turkish older siblings, Turkish younger siblings, English older siblings, and English younger siblings. Latent parenting construct and latent problem behaviours construct are defined as a single measure to describe observed variables.

Before the structural model was tested, two measurement models were conducted through confirmatory factor analysis with loadings for the item with the largest factor loading (the referent). MGCFA tested Measurement Invariance (MI) across groups. To fit our model, the following steps were applied (Meredith \& Teresi, 2006; Vandenberg \& Lance, 2000). (1) Equal form also known as configural invariance, which requires that the number of factors and pattern of loadings of indicators on factors is the same across groups, (2) equal factor loadings, also known as weak factorial invariance, which requires that, in addition to configural invariance, the slopes (factor loadings) are invariant across groups, (3) equal indicator intercepts also known as strong factorial invariance, also requires that the intercepts are invariant across all groups. The process of fitting these invariant models from configural to strong factorial invariance results in a nested structure of models in which each model includes all the constraints of the previous model. These first three steps are necessary to establish measurement invariance and to compare scores (means of the latent variable) across groups (Milfont \& Fischer, 2010). Comsa (2010) also emphasizes that meaningful interpretation of the compared scores across cultures requires that three levels of invariance are fulfilled. However, in practical applications, failure of full measurement invariance (i.e. all parameters are equal across groups) is common (Vandenberg \& Lance, 2000). In this case, Byrne et al. (1989) suggest testing for partial measurement invariance (i.e. some but not all measurement parameters are invariant across all groups). Chi-square statistics were used to test whether additional constraints resulted in a worsening of model fit (Kankaras \& Moors, 2010).

\section{Results}

Descriptive statistics for all study measures are presented in Table 1.

\section{Parenting measurement model}

The latent parenting variable was measured by six observed variables (observed positive affect, observed negative affect, BPI warmth, BPI hostility, mother-rated positivity, and mother-rated negativity). Observed positive affect emerged as the referent indicator. Our baseline multiple-group analysis with no equality constraints imposed was conducted 
Table 1. Means and (SDs) of study measures.

\begin{tabular}{|c|c|c|c|c|}
\hline & \multicolumn{2}{|c|}{ Turkey } & \multicolumn{2}{|c|}{ England } \\
\hline & $\begin{array}{l}\text { Older sibling } \\
\quad N=100\end{array}$ & $\begin{array}{l}\text { Younger sibling } \\
\qquad=100\end{array}$ & $\begin{array}{l}\text { Older sibling } \\
\quad N=118\end{array}$ & $\begin{array}{c}\text { Younger sibling } \\
N=118\end{array}$ \\
\hline \multicolumn{5}{|l|}{ Parenting questionnaires } \\
\hline Mother-rated positivity & $4.11(.45)$ & $4.23(.33)$ & $4.15(.35)$ & $4.16(.35)$ \\
\hline Mother-rated negativity & $1.45(.34)$ & $1.26(.35)$ & $1.24(.26)$ & $1.22(.30)$ \\
\hline \multicolumn{5}{|l|}{ Berkeley Puppet Interview } \\
\hline Warmth & $5.68(.53)$ & $5.35(.69)$ & $5.63(.64)$ & $5.45(.70)$ \\
\hline Hostility & $3.01(.86)$ & $3.17(.90)$ & $3.53(1.04)$ & $3.37(1.00)$ \\
\hline \multicolumn{5}{|l|}{ Etch-a-Sketch task } \\
\hline Observed positive affect & $3.93(1.19)$ & $4.03(1.11)$ & $4.26(1.17)$ & $4.07(1.16)$ \\
\hline Observed negative affect & $1.74(1.03)$ & $1.39(.88)$ & $1.09(.37)$ & $1.06(.32)$ \\
\hline \multicolumn{5}{|l|}{ Problem behaviours } \\
\hline Hyperactivity & $4.32(2.57)$ & $4.16(2.46)$ & $3.85(.2 .46)$ & $4.03(2.59)$ \\
\hline Emotional problems & $2.83(2.27)$ & $2.12(1.97)$ & $2.63(2.33)$ & $2.07(1.62)$ \\
\hline Conduct problems & $1.93(1.70)$ & $1.86(1.63)$ & $1.83(1.46)$ & $2.15(1.63)$ \\
\hline Peer problems & $2.68(1.81)$ & $2.89(1.92)$ & 1. $74(1.68)$ & $1.57(1.39)$ \\
\hline
\end{tabular}

with four groups: Turkish older siblings, Turkish younger siblings, English older siblings, and English younger siblings. Configural invariance was obtained by making the number of items and their associated constructs the same across the four groups. According to $\mathrm{Hu}$ and Bentler (1999), the Root Mean Square Error of Approximation (RMSEA) values close to .06 or below, and Comparative Fit Index (CFI) values close to .95 or above indicate good fit. Goodness-of-fit statistics revealed that the model fit the data adequately (see Table 4). In order to maximize fit, modification indices were examined, leading us to include an error covariance between BPI warmth and BPI hostility with an estimate of error covariance -.16. As stated by Byrne et al. (1989), it is often necessary to allow for correlated errors to obtain a well-fitting model. Incorporating correlated errors to the model is justified as these errors might represent a method effect that might arise from the item format of the subscales of the same measuring instrument such as similarities in wording or method of measurement. Modification indices are examined as a guide for identifying where model misspecification lies. BPI scale is based on the reports from young children about their relationship with their mothers, indicating a different method of measurement from other scales in the study which are all based on mother reports.

For the weak factorial invariance model, measurement weights (factor loadings) were constrained to be equal across groups. For the strong factorial invariance model, measurement intercepts were also constrained to be equal across groups. The models yielded significant chi-square differences compared to the unconstrained model, indicating that the not all factor loadings and intercepts were equal across groups. In practical applications, failure of full measurement variance is common (Vandenberg \& Lance, 2000). In this case, Byrne et al. (1989) suggest testing for partial measurement invariance where some but not all measurement parameters are invariant across all groups. Chi-square difference tests were used on a parameter-by-parameter basis.

The factor loadings for BPI warmth, BPI hostility and mother-rated negativity, as well as intercepts for BPI warmth, BPI hostility, mother-rated negativity, and observed negative affect were variant across groups (see Figure 1 and Table 2). Mother-rated negativity had more substantial loadings on the latent parenting construct for the English families than for the Turkish families. By contrast, observed positive affect had more substantial 


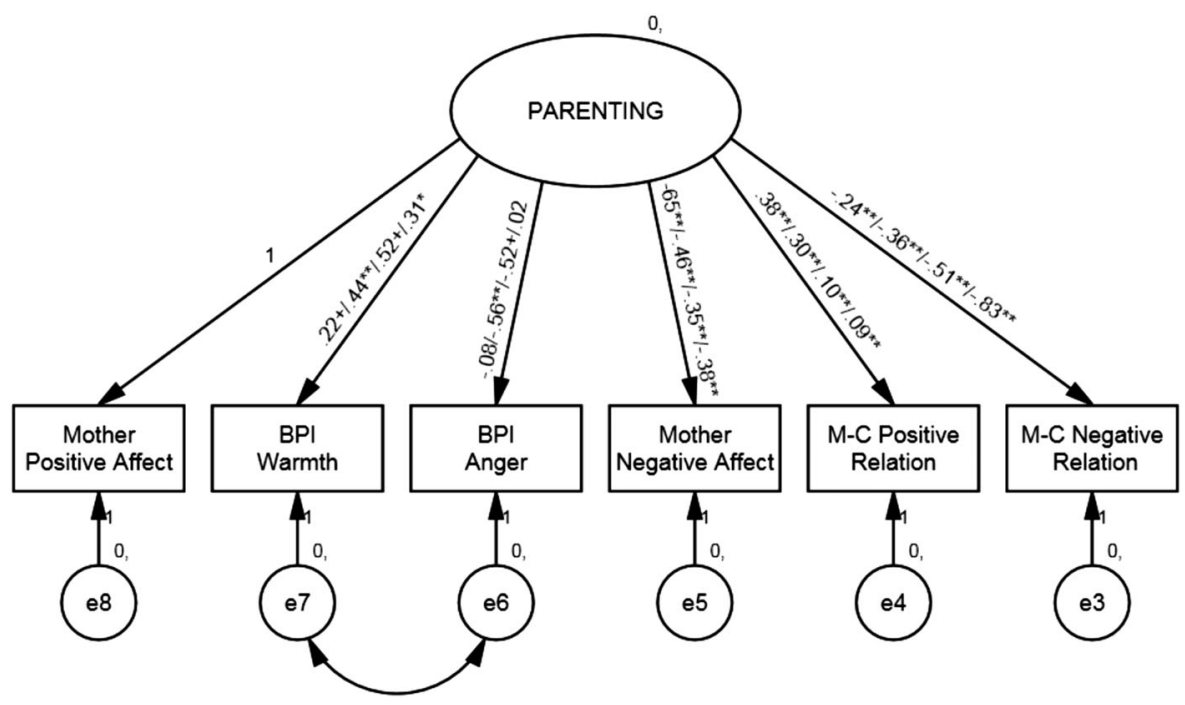

Figure 1. Standardized estimates for measurement model for parenting (Turkish older siblings \Turkish younger siblings\English older siblings\English younger siblings). ${ }^{* * *} p<.001,{ }^{* *} p<.01$, ${ }^{*} p<.05,+p<.10$.

loadings for the Turkish families than for the English families. In the case of BPI warmth, the Turkish older siblings were out of step with the other three groups - BPI warmth did not load significantly on to the latent parenting construct for the Turkish older siblings as it did for the other children's puppet reports. Finally, BPI hostility yielded significant and substantial loadings for the English older siblings and Turkish younger siblings, but loadings were negligible for the English younger siblings and Turkish older siblings.

Full configural variance along with partial weak and strong factorial invariance was revealed. Inspection of the variant intercepts indicates that mother-rated negativity was highest for Turkish older siblings, as was observed negative affect. Older siblings from both countries reported more warmth from mothers than did their younger siblings. Finally, the English children reported more hostility from their mothers than did the Turkish children (see Table 2).

Table 2. Factor loadings and intercepts for the parenting measurement model.

\begin{tabular}{|c|c|c|c|c|c|c|c|c|}
\hline & \multicolumn{4}{|c|}{ Factor loadings } & \multicolumn{4}{|c|}{ Item intercepts } \\
\hline & $\begin{array}{l}\text { English } \\
\text { OS }\end{array}$ & $\begin{array}{l}\text { English } \\
\text { YS }\end{array}$ & $\begin{array}{l}\text { Turkish } \\
\text { OS }\end{array}$ & $\begin{array}{l}\text { Turkish } \\
\text { YS }\end{array}$ & $\begin{array}{l}\text { English } \\
\text { OS }\end{array}$ & $\begin{array}{l}\text { English } \\
\text { YS }\end{array}$ & $\begin{array}{l}\text { Turkish } \\
\text { OS }\end{array}$ & $\begin{array}{c}\text { Turkish } \\
\text { YS }\end{array}$ \\
\hline $\begin{array}{l}\text { Mother-rated } \\
\text { positivity }\end{array}$ & $.10^{A}$ & $.09^{A}$ & $.38^{A}$ & $.30^{A}$ & $4.17^{x}$ & $4.17^{x}$ & $4.17^{x}$ & $4.17^{x}$ \\
\hline $\begin{array}{l}\text { Mother-rated } \\
\text { negativity }\end{array}$ & $-.51^{\mathrm{A}}$ & $-.83^{\mathrm{A}}$ & $-.24^{\mathrm{B}}$ & $-.36^{\mathrm{B}}$ & $1.25^{x}$ & $1.21^{x}$ & $1.44^{Y}$ & $1.26^{\mathrm{Z}}$ \\
\hline $\begin{array}{l}\text { Observed positive } \\
\text { affect }\end{array}$ & $.17^{\mathrm{A}}$ & $.17^{\mathrm{A}}$ & $.84^{\mathrm{B}}$ & $.58^{\mathrm{B}}$ & $4.08^{x}$ & $4.08^{x}$ & $4.08^{x}$ & $4.08^{x}$ \\
\hline $\begin{array}{l}\text { Observed negative } \\
\text { affect }\end{array}$ & $-.35^{\mathrm{A}}$ & $-.38^{\mathrm{A}}$ & $-.65^{\mathrm{A}}$ & $-.46^{\mathrm{A}}$ & $1.10^{x}$ & $1.06^{x}$ & $1.66^{Y}$ & $1.39^{z}$ \\
\hline BPI warmth & $.52^{\mathrm{A}_{*}}$ & $.31^{\mathrm{A}}$ & $-.22^{\mathrm{B}}$ & $.44^{c}$ & $5.63^{x}$ & $5.45^{Y}$ & $5.69^{\mathrm{z}}$ & $5.34^{\mathrm{w}}$ \\
\hline BPI hostility & $.52^{\mathrm{A}_{*}}$ & $.02^{\mathrm{B}}$ & $-.08^{\mathrm{C}}$ & $-.56^{\mathrm{D}}$ & $3.54^{x}$ & $3.37^{x}$ & $3.00^{Y}$ & $3.18^{Y}$ \\
\hline
\end{tabular}

Notes: OS = Older sibling, YS = Younger sibling, BPI = Berkeley Puppet Interview; bolded factor loadings indicate $p<.05$. Factor loadings with *are marginally significant, $p<.07$; factor loadings with different letters across a row are variant. 


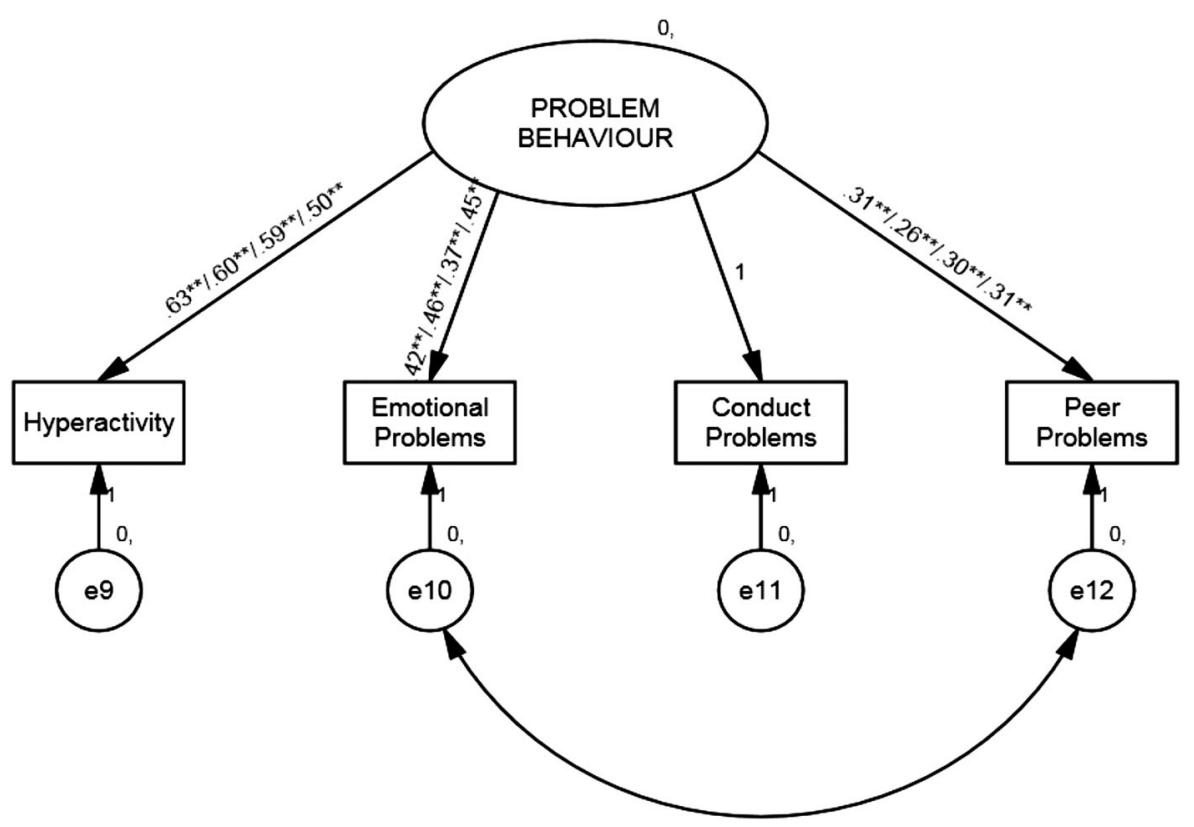

Figure 2. Standardized estimates for measurement model for problem behaviours (Turkey older sibling ITurkey younger sibling\England older sibling \England younger sibling). ${ }^{* * *} p<.001,{ }^{* *} p<.01,{ }^{*} p<.05$, $+p<.10$.

\section{Problem behaviour measurement model}

The latent problem behaviour variable was measured by four observed variables (hyperactivity, conduct problems, emotional problems, and peer problems) (see Figure 2). Conduct problems emerged as the referent indicator. Goodness-of-fit statistics revealed that the model fit the data adequately (see Table 4). Examination of modification indices leads us to include an error covariance between emotional problems and peer problems with an estimate of error covariance .09. This type of modelling also enables one to incorporate parameters that are not considered as related first hand. As Eisenberg et al. (2001) indicated, sadness, anxiety, fear, and distress in response to minor aversive stimuli are believed to predict internalizing problems. Similarly, in our study, both peer problems representing aversive stimuli, such as shyness and social withdrawal, and emotional problems, such as higher levels of sadness, anxiety, fear, shame, and depression, implicitly represent same underlying construct, also known as internalizing problems. Adding covariance between emotional problems and peers problems supports the statement made by Eisenberg et al. (2001).

Again, a baseline multiple-group model analysis with no equality constraints imposed was conducted with four groups: Turkish older siblings, Turkish younger siblings, English older siblings, and English younger siblings. Configural invariance was obtained by making the number of items and their associated constructs the same across four groups. A non-significant chi-square difference between the weak factorial invariance model and the unconstrained model indicated that factor loadings were invariant across groups. However, the chi-square difference test between the unconstrained model and the strong factorial invariance model was significant, suggesting 
Table 3. Factor loadings and intercepts for the problem behaviours measurement model.

\begin{tabular}{|c|c|c|c|c|c|c|c|c|}
\hline & \multicolumn{4}{|c|}{ Factor loadings } & \multicolumn{4}{|c|}{ Item intercepts } \\
\hline & $\begin{array}{l}\text { English } \\
\text { OS }\end{array}$ & $\begin{array}{c}\text { English } \\
\text { YS }\end{array}$ & $\begin{array}{l}\text { Turkish } \\
\text { OS }\end{array}$ & $\begin{array}{c}\text { Turkish } \\
\text { YS }\end{array}$ & $\begin{array}{l}\text { English } \\
\text { OS }\end{array}$ & $\begin{array}{l}\text { English } \\
\text { YS }\end{array}$ & $\begin{array}{c}\text { Turkish } \\
\text { OS }\end{array}$ & $\begin{array}{c}\text { Turkish } \\
\text { YS }\end{array}$ \\
\hline Hyperactivity & $.62^{A}$ & $.52^{A}$ & $.67^{A}$ & $.63^{A}$ & $4.08^{X}$ & $4.08^{X}$ & $4.08^{X}$ & $4.08^{X}$ \\
\hline $\begin{array}{l}\text { Emotional } \\
\text { problems }\end{array}$ & $.43^{A}$ & $.54^{\mathrm{A}}$ & $.49^{A}$ & $.52^{A}$ & $2.30^{X}$ & $2.30^{x}$ & $2.30^{x}$ & $2.30^{x}$ \\
\hline Conduct problems & $.90^{\mathrm{A}}$ & $.68^{A}$ & $.85^{A}$ & $.83^{A}$ & $1.91^{x}$ & $1.91^{\mathrm{X}}$ & $1.91^{X}$ & $1.91^{x}$ \\
\hline Peer problems & $.34^{\mathrm{A}}$ & $.37^{A}$ & $.35^{A}$ & $.29^{A}$ & $1.77^{x}$ & $1.76^{x}$ & $2.64^{Y}$ & $2.91^{Y}$ \\
\hline
\end{tabular}

Notes: OS = Older Sibling, YS = Younger Sibling, BPI = Berkeley Puppet Interview; bolded factor loadings indicate $p<.05$; factor loadings with different letters across a row are variant.

that full strong factorial invariance did not hold for this model. In the final model, all the factor loadings of the problem behaviour construct, intercepts for hyperactivity, conduct problems, and emotional problems were identified as invariant across groups. In contrast, the intercept for peer problems indicated that the Turkish children demonstrated more difficulties in their peer relations than did their English peers (see Figure 2 and Table 3).

\section{Structural model}

A full structural model of the link between parenting and problem behaviours including all the invariant parameters from both measurement models yielded a significant chi-square $\left(\chi^{2}(158)=237.73, p=.00\right)$. However, the CFI was .86, and the RMSEA was .03. We conclude that although the CFI score is less than the recommended cut-off criterion, this model provides a reasonable fit to the data due to its low RMSEA score.

All model fit statistics are shown in Table 4. The association between parenting and problem behaviour is significant for all groups (see Figure 3); poorer quality parenting was associated with more problem behaviours. This link was substantial for the English families (averaging -.47) but only modest to moderate for the Turkish families (averaging -.24). This cultural difference was statistically significant.

\section{Discussion}

We investigated the link between parenting and child problem behaviour across cultures, using a multi-informant approach. MGCFA was used to test MI across groups, as well as

Table 4. Model fit statistics for all models.

\begin{tabular}{lcccc}
\hline Scale and model & Chi-square $\left(x^{2}\right)$ & $\mathrm{df}$ & CFI & RMSEA \\
\hline Parenting measurement model & & & & \\
$\quad$ Configural & $51.54^{*}$ & 32 & .90 & .04 \\
Weak factorial & $59.82^{*}$ & 38 & .88 & .04 \\
$\quad$ Strong factorial & $69.40^{*}$ & 44 & .86 & .04 \\
Problem behaviours measurement model & $60.12^{* *}$ & & .82 & .12 \\
$\quad$ Configural & $64.52^{* *}$ & 17 & .84 & .08 \\
Weak factorial & $85.68^{* *}$ & 26 & .80 & .07 \\
Strong factorial & & & & \\
Structural model & $189.44^{* *}$ & 128 & .89 & .03 \\
Configural & $207.31^{* *}$ & 143 & .88 & .03 \\
Weak factorial & $237.73^{* *}$ & 158 & .86 & .03 \\
Strong factorial & & & & \\
\hline
\end{tabular}

${ }^{*} p<.05$.

${ }^{* *} p<.01$. 


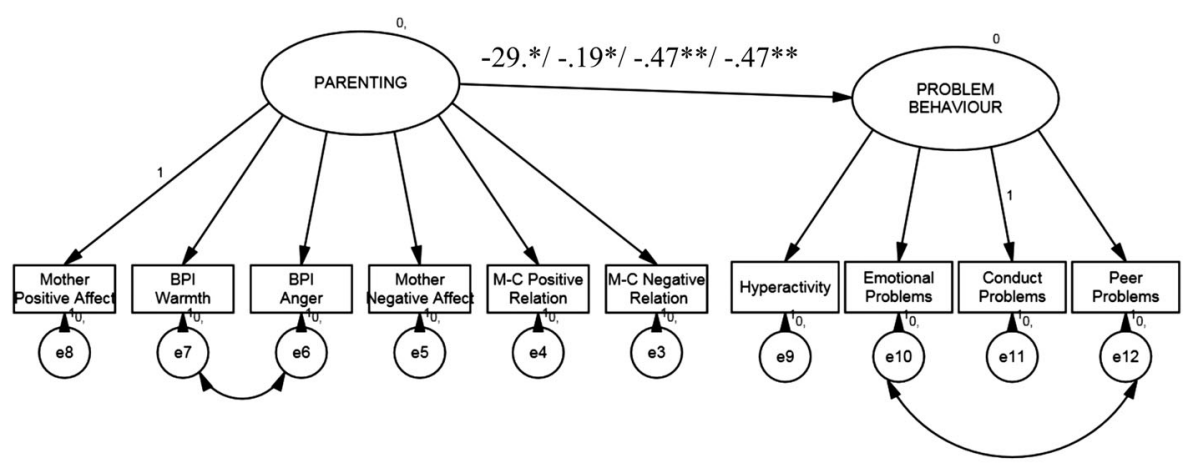

Figure 3. Standardized estimates for the structural model (Turkey older sibling \Turkey younger sibling \England older sibling\England younger sibling). ${ }^{* * *} p<.001,{ }^{* *} p<.01,{ }^{*} p<.05,+p<.10$.

testing the structural model. Parenting and child behaviours were substantially linked for the English sample, but only moderately so for the Turkish sample. Before interpreting this main finding, cultural issues of measurement are discussed. Finally, study limitations as well as implications and future directions for research are outlined.

\section{Measurement}

Although the parent-child relationship is important in all cultures, specific contexts that are associated with particular parenting strategies result in culture-specific developmental pathways (Kärtner, Holodynski, \& Wörmann, 2013). Even when the same standardized assessment procedures are used across cultures, it is not always clear whether differences in ratings are caused by true cultural differences (Bengi-Arslan, Verhulst, Van der Ende, \& Erol, 1997) or by culturally specific meanings attached to those behaviours. Our first research question addressed the measurement of motherchild relationship quality. Although lack of measurement invariance in cross-cultural research is very common, especially when researchers use an instrument developed for one culture in other cultures (Huang et al., 2011), partial measurement invariance, some but not all measurement parameters are invariant across all groups, was revealed in our study.

The factor loading results indicate that for the English families, mother-rated negativity is particularly central to the underlying construct of parenting, whereas for the Turkish families observed positive affect was the central feature. Less consistent patterns emerged from the children's puppet reports. The intercept results indicated more negativity from Turkish mothers according to coded observations and the mothers themselves, but the reverse pattern emerged from the children's puppet reports. These results contradict the assumption that measures have the same meaning within cultures, let alone between cultures. The reasons for cross-cultural non-equivalence may include translation challenges, different interpretations of questions, and different socially desirable answers across cultures (Byrne \& Watkins, 2003). Alongside these methodological interpretations, we argue that the concept of parenting itself is culturally variable. Culture influences behaviour, as well as how that behaviour is perceived and evaluated. Parental behaviours and beliefs are guided by general cultural norms that lead parents to interpret and respond 
to child behaviours in accordance with culturally prescribed expectations, which in turn modify outcomes of behavioural development (Chen et al., 1998).

Including multiple reporters of mothering helps to triangulate on an interpretation of the cross-cultural findings. Observers' and mothers' ratings were reasonably consistent in showing that although the Turkish mothers were more negative in their parenting, it was the degree of warmth rather than negativity that was the defining feature of parenting quality among the Turkish families. Verbal criticism by parents in Turkey is a more commonly used method than it is in the U.K. (Kagitcibasi, 1989); threats such as abandoning the family and withholding love because of a child's misbehaviour are also common among Turkish mothers (Yorukoglu, 1987). Turkish mothers use criticism as a means of education; if the criticism is not excessive, we speculate that cultural norms may lead to it being perceived as care and attention. We propose that the maternal negativity may be a form of guidance, but that less warmth may be interpreted as a withdrawal of love. Through such perceptual filters, it is understandable that warmth would be the more salient feature of parenting.

Our second research question addressed the measurement of children's adjustment via maternal reports. The only variant aspect was the intercept of peer problems between England and Turkey; Turkish mothers reported that they had more peer problems than did their English counterparts. In collectivistic cultures, there is a strong requirement for loyalty and commitment to the group, and great pressure on group members to identify with the group and conform to group norms (see Chen \& French, 2008). This may create pressure for children and elevated expectations from parents. Also, as stated by Bengi-Arslan et al. (1997), there is a tendency among Turkish parents (when compared to Dutch parents) to score their children as having more adjustment problems; the difference may be in parental reporting rather than actual differences in child behaviour.

\section{Parenting-child adjustment}

Georgas (2003) states that there are two approaches when trying to understand a psychological phenomenon from a cultural viewpoint: an indigenous and a cross-cultural perspective. The indigenous approach is the vertical dimension - understanding psychological phenomena in terms of an individual culture. The cross-cultural approach is the horizontal dimension - understanding psychological phenomena by comparing cultures. The current study has the advantage of including both horizontal and vertical dimensions. Simple mean comparisons between England and Turkey would have masked the more moderate link between parenting and child behaviour in Turkey.

Given the more central role of negativity in the parenting construct among the English families, the stronger link between parenting and child problem behaviour among the English is consistent with previous findings among European Americans in contrast to African Americans (Deater-Deckard \& Dodge, 1997). The meaning that children attach to a specific parenting behaviour (e.g. hugging, smacking) varies across cultures (Deater-Deckard \& Dodge, 1997). Parents might select parenting practices (e.g. punishment, reasoning) that best teach children about the behaviours that reflect the cultural values (Calzada, Fernandez, \& Cortes, 2010). Deater-Deckard and Dodge (1997) also suggest that in cultures where physical punishment is a predominant and normative form of discipline, harsh discipline might be seen as acceptable; children may not 
necessarily perceive it as negative. We found more cultural variance for the negativity measures, indicating that a culturally sensitive understanding of negative parenting behaviours is warranted.

The more modest association between mothering and child behaviour in Turkey also implies that additional unmeasured factors are important in the development of children's behaviour. It may be that additional aspects of mothering are more salient in Turkey perhaps differentiated aspects of positivity. Of course, the current study only assessed mothering, and the quality of the father-child relationship also plays a key role in child development (Lamb, 2010). Extra-parental factors may also be more important in this more collectivistic, group-oriented culture.

\section{Limitations and future directions}

Although the current study had many strengths, including objective coded observations alongside maternal and child reports, we acknowledge some limitations. First, we examined only two countries. Replication of this study with many countries would be beneficial as parents and children from different countries may experience distinct family processes. Such a replication would indicate whether the results seen in this study are unique to Turkish compared to English families, or whether they can be generalized to countries categorized as collectivistic or individualistic. Moreover, more extensive areas within each country should be included to have more representative samples of cultures.

When designing the study in Turkey, we used similar methods to a pre-existing study, hence a gap in time occurred. The cross-cultural comparisons may possibly be confounded by potential cohort differences. However, sociocultural systems have special natures and their properties gradually change within time (Allen \& Bentz, 1965), and systematic changes mostly follow economic development (Inglehart \& Oyserman, 2004; Kagitcibasi, 2012). Given the stability of economy of Turkey over the years, seven-year time gap might not necessarily lead to a sociocultural change that would have an effect on associations between global measures of parenting and child adjustment.

As this study was not longitudinal or experimental, conclusions cannot be made about cause and effect. That is, although we have conceptualized the link in one direction, namely parenting as influencing child behaviour, child behaviour also elicits different parenting behaviours (Bell, 1968). Replication of this study including a longitudinal component will be necessary in order to assess the temporal sequence of parenting-child behaviour links. In addition, more families will be required to test more complex models and to uncover smaller, though systematic effects. Including fathers, both as key family members, as well as additional informants on family dynamics and behaviours will strengthen the study. Future research can also benefit from investigating the link between specific dimensions of parenting and specific domains of child adjustment such as internalizing and externalizing problems between Turkish and English families. The present study explored parent-child relationship using BPI scale as a source of child perspective and parent-child relation scale as a source of mothers' perspective. Future work could benefit from other measures with the aim of measuring how children and parents perceive their relations with each other by including a large range of dimensions of the parent-child relation, instead of only focusing warmth and hostility dimensions. 


\section{Conclusions}

Since ideas about optimal parenting and desired child outcomes depend on cultural values and belief systems, a single parenting-child behaviour equation may not apply to all cultures. Most of the extant knowledge on parental behaviour and children's outcomes comes from Western cultures (Atzaba-Poria, 2010), and our findings indicate that studies including other cultures are key in order to identify indigenous cultural constructs. A culturally sensitive understanding of family relations and child behaviours can guide researchers in developing more effective intervention programmes that are needed, particularly in multicultural societies.

\section{Key points}

- The construct "mothering quality" varies between English and Turkish cultures.

- Maternal negativity is more central to "mothering quality" in England whereas positive features may be more pivotal for Turkish families.

- Mothering quality was more strongly linked to children's adjustment in England than in Turkey.

\section{Acknowledgements}

This research was supported by grants from the Joseph Rowntree Foundation and a fellowship awarded to the first author from the Ministry of Turkish Education. We thank Anna Harrison and Joanne Coldwell for coordinating the project with English families, and Eva Syngelaki and Christopher Illingworth for their assistance in data collection. Finally, we are grateful to the schools and families that participated in this project. This paper's findings are based on the first author's doctorate thesis.

\section{Disclosure statement}

No potential conflict of interest was reported by the authors.

\section{ORCID}

Alison Pike (i) http://orcid.org/0000-0001-5795-6159

\section{References}

Ablow, J. C., \& Measelle, J. R. (1993). Berkeley puppet interview: Administration and scoring system manuals. Berkeley: University of California.

Adamsons, K., \& Buehler, C. (2007). Mothering versus fathering versus parenting: Measurement equivalence in parenting measures. Parenting: Science and Practice, 7(3), 271-303.

Allen, F. R., \& Bentz, W. K. (1965). Toward the measurement of sociocultural change. Social Forces, 43(4), 522-532.

Arbuckle, J. L. (2007). Amos 16.0 user's guide. Spring House, PA: Amos Development Corporation. 
Ataca, B. (2009). Turkish family structure and functioning. In S. Bekman \& A. Aksu-Koc (Eds.), Perspectives on human development, family, and culture (pp. 108-125). New York, NY: Cambridge University Press.

Atzaba-Poria, N. (2010). Internalizing and externalizing problems in early childhood: A study of former Soviet Union and Veteran-Israeli children living in Israel. Journal of Cross-Cultural Psychology, 42, 983-997.

Atzaba-Poria, N., Pike, A., \& Deater-Deckard, K. (2004). Do risk factors for problem behaviour act in a cumulative manner? An examination of ethnic minority and majority children through an ecological perspective. Journal of Child Psychology and Psychiatry, 45, 707-718.

Bell, R. Q. (1968). A reinterpretation of the direction of effects in studies of socialization. Psychological Review, 75, 81-95.

Bengi-Arslan, L., Verhulst, F. C., Van der Ende, J., \& Erol, N. (1997). Understanding childhood (problem) behaviors from a cultural perspective: Comparison of problem behaviors and competencies in Turkish immigrant, Turkish and Dutch children. Social Psychiatry and Psychiatric Epidemiology, 32, 477-84.

Bornstein, M. H., \& Cheah, C. S. L. (2006). The place of "culture and parenting" in the ecological contextual perspective on developmental science. In K. H. Rubin \& O. B. Chung (Eds.), Parenting beliefs, behaviors, and parent-child relations: A cross-cultural perspective (pp. 3-33). Hove: Psychology Press.

Bronfenbrenner, U. (1979). The ecology of human development: Experiments by nature and design. Cambridge, MA: Harvard University Press.

Byrne, B. M., Shavelson, R. J., \& Muthen, B. (1989). Testing for the equivalence of factor covariance and mean structures: The issue of partial measurement invariance. Psychological Bulletin, 105, 456-466.

Byrne, B. M., \& Watkins, D. (2003). The issue of measurement invariance revisited. Journal of Cross-Cultural Psychology, 34, 155-175.

Calzada, E. J., Fernandez, Y., \& Cortes, D. E. (2010). Incorporating the cultural value of respeto into a framework of Latino parenting. Cultural Diversity and Ethnic Minority Psychology, 16, 77-86.

Campbell, S. B. (1995). Behavior problems in preschool children: A review of recent research. Journal of Child Psychology and Psychiatry, and Allied Disciplines, 36, 113-49.

Caspi, A., Moffitt, T. E., Morgan, J., Rutter, M., Taylor, A., Arseneault, L., ... Polo-Tomas, M. (2004). Maternal expressed emotion predicts children's antisocial behavior problems: Using monozygotic-twin differences to identify environmental effects on behavioral development. Developmental Psychology, 40, 149-161.

Chan, K., Penner, K., Mah, J. W., \& Johnston, C. (2010). Assessing parenting behaviors in EuroCanadian and East Asian immigrant mothers: Limitations to observations of responsiveness. Child \& Family Behavior Therapy, 32, 85-102.

Chen, X., \& French, D. C. (2008). Children's social competence in cultural context. Annual Review of Psychology, 59, 591-616.

Chen, X., Hastings, P. D., Rubin, K. H., Chen, H., Cen, G., \& Stewart, S. L. (1998). Child-rearing attitudes and behavioral inhibition in Chinese and Canadian toddlers: A cross-cultural study. Developmental Psychology, 34, 677-686.

Choe, D. E., Olson, S. L., \& Sameroff, A. J. (2013). The interplay of externalizing problems and physical and inductive discipline during childhood. Developmental Psychology, 4, 1-11.

Collins, W. A., Madsen, S. D., \& Susman-Stillman, A. (2005). Parenting during middle childhood. Handbook of Parenting, 1, 73-101.

Comsa, M. (2010). How to compare means of latent variables across countries and waves: Testing for invariance measurement. An application using Eastern European societies. Sociológia, 42(6), 639-669.

Deater-Deckard, K. (2000). Parenting and child behavioral adjustment in early childhood: A quantitative genetic approach to studying family processes. Child Development, 71, 468-484.

Deater-Deckard, K., \& Dodge, K. A. (1997). Externalizing behavior problems and discipline revisited: Nonlinear effects and variation by culture, context, and gender. 
Psychological Inquiry: An International Journal for the Advancement of Psychological Theory, 8, 161-175.

Deater-Deckard, K., Dodge, K. A., Bates, J. E., \& Pettit, G. S. (1996). Physical discipline among African American and European American mothers: Links to children's externalizing behaviors. Developmental Psychology, 32, 1065.

Deater-Deckard, K., Pylas, M. V., \& Petrill, S. A. (1997). The Parent-child interaction system (PARCHISY). London: Institute of Psychiatry.

Dunn, J. (2002). Sibling relationships. In P. K. Smith \& C. H. Hart (Eds.), Blackwell handbook of childhood social development (pp. 223-237). Oxford: Blackwell.

Dunn, J. A., \& Plomin, R. (1990). Separate lives: Why siblings are so different. New York, NY: Basic Books.

Dwairy, M. (2010). Introduction to special section on cross-cultural research on parenting and psychological adjustment of children. Journal of Child and Family Studies, 19, 1-7.

Eisenberg, N., Cumberland, A., Spinrad, T. L., Fabes, R. A., Shepard, S. A., Reiser, M., ... Guthrie, I. K. (2001). The relations of regulation and emotionality to children's externalizing and internalizing problem behavior. Child Development, 72(4), 1112-1134.

Erez, M., \& Gati, E. (2004). A dynamic, multi-level model of culture: From the micro level of the individual to the macro level of a global culture. Applied Psychology, 53, 583-598.

Fraser, M. W. (1996). Aggressive behavior in childhood and early adolescence: An ecological-developmental perspective on youth violence. Social Work, 41, 347-361.

Georgas, J. (2003). Family: Variations and changes across cultures. Online Readings in Psychology and Culture, Unit 6. Retrieved from http://scholarworks.gvsu.edu/orpc/vol6/iss3/3

Gomez, R., \& Rohner, R. P. (2011). Tests of factor structure and measurement invariance in the United States and Australia using the adult version of the parental acceptance-rejection questionnaire. Cross-Cultural Research, 45(3), 267-285.

Goodman, R. (1997). The strengths and difficulties questionnaire: A research note. Journal of Child Psychology and Psychiatry and Allied Disciplines, 38, 581-586.

Greenfield, P. M., Keller, H., Fuligni, A., \& Maynard, A. (2003). Cultural pathways through universal development. Annual Review of Psychology, 54(1), 461-490.

Harkness, S., \& Super, C. M. (2006). Themes and variations: Parental ethnotheories in Western cultures. In K. H. Rubin \& O. B. Chung (Eds.), Parenting beliefs, behaviors, and parent-child relations: A cross-cultural perspective (pp. 61-79). New York: Psychology press.

Hetherington, E. M., \& Clingempeel, U. G. (1992). Coping with marital transitions: A family systems perspective. Monographs of the Society for Research in Child Development, 57, 1-128 (2-3, Serial No. 227).

Ho, C., Bluestein, D. N., \& Jenkins, J. M. (2008). Cultural differences in the relationship between parenting and children's behavior. Developmental Psychology, 44, 507-522.

Hu, L. T., \& Bentler, P. M. (1999). Cutoff criteria for fit indexes in covariance structure analysis: Conventional criteria versus new alternatives. Structural Equation Modeling: A Multidisciplinary Journal, 6(1), 1-55.

Huang, L., Malone, P. S., Lansford, J. E., Deater-Deckard, K., Di Giunta, L., Bombi, A. S., ... Pastorelli, C. (2011). Measurement invariance of discipline in different cultural contexts. Family Science, 2(3), 212-219.

Imamoglu, E. O. (1998). Individualism and collectivism in a model and scale of balanced differentiation and integration. The Journal of Psychology, 132, 95-105.

Inglehart, R., \& Oyserman, D. (2004). Individualism, autonomy, self-expression. The human development syndrome. In H. Vinken, J. Soeters, \& P. Ester (Eds.), Comparing cultures, dimensions of culture in a comparative perspective (pp. 74-96). Leiden: Brill.

Johnson, P. (2006). Methods and frameworks for crosscultural measurement. Medical Care, 44, S17-S20.

Kagitcibasi, C. (1989). Family and socialization in cross-cultural perspective: A model of change. In V. Berman (Ed.), Nebraska symposium on motivation (pp. 135-200). Lincoln, NE: University of Nebraska Press. 
Kagitcibasi, C. (2007). Family, self, and human development across cultures: Theory and applications (2nd ed.). Hillsdale, NJ: Erlbaum.

Kagitcibasi, C. (2012). Sociocultural change and integrative syntheses in human development: Autonomous-related self and social-cognitive competence. Child Development Perspectives, 6 (1), 5-11.

Kankaras, M., \& Moors, G. (2010). Researching measurement equivalence in cross-cultural studies. Psihologija, 43, 121-136.

Kärtner, J., Holodynski, M., \& Wörmann, V. (2013). Parental ethnotheories, social practice and the culture-specific development of social smiling in infants. Mind, Culture, and Activity, 20, 79-95.

Keller, H., Lamm, B., Abels, M., Yovsi, R., Borke, J., Jensen, H., Papaligoura, Z., ... Chaudhary, N. (2006). Cultural models, socialization goals, and parenting ethnotheories: A Multicultural analysis. Journal of Cross-Cultural Psychology, 37, 155-172.

Kotchick, B. A., \& Forehand, R. (2002). Putting parenting in perspective : A discussion of the contextual factors that shape parenting practices. Journal of Child and Family Studies, 11, 255-269.

Lamb, M. E. (2010). The role of the father in child development (5th ed.). New York, NY: Wiley.

Lansford, J. E. (2010). The special problem of cultural differences in effects of corporal punishment. Law and Contemporary Problems, 73(2), 89-106.

Lerner, R. M., \& Lerner, J. V. (1987). Children in their contexts: A goodness-of-fit model. In J. B. Lancaster, J. Altmann, A. S. Rossi, \& L. R. Sherrod (Eds.), Parenting across the life span: Biosocial dimensions (pp. 377-404). New York, NY: Social Science Research Council.

LeVine, R. A. (1988). Human parental care: Universal goals, cultural strategies, individual behavior. New Directions for Child and Adolescent Development, 40, 3-12.

Loeber, R. (1990). Development and risk factors of juvenile antisocial behavior and delinquency. Clinical Psychology Review, 10, 1-41.

Luk, J. W., King, K. M., McCarty, C. A., Vander Stoep, A., \& McCauley, E. (2016, March 10). Measurement invariance testing of a three-factor model of parental warmth, psychological control, and knowledge across European and Asian/Pacific islander American youth. Asian American Journal of Psychology, 7(2), 97-107. doi:10.1037/aap0000040

Mäntymaa, M., Puura, K., Luoma, I., Vihtonen, V., Salmelin, R. K., \& Tamminen, T. (2009). Child's behaviour in mother-child interaction predicts later emotional and behavioural problems. Infant and Child Development, 18, 455-467.

Meredith, W., \& Teresi, J. a. (2006). An essay on measurement and factorial invariance. Medical Care, 44, S69-S77.

Milfont, T. L., \& Fischer, R. (2010). Testing measurement invariance across groups: Applications in cross-cultural research. International Journal of Psychological Research, 3(1), 111-121.

Ogbu, J. U. (1981). Origins of human competence: A cultural-ecological perspective. Child Development, 52, 413-429.

Oyserman, D. (2011). Culture as situated cognition: Cultural mindsets, cultural fluency, and meaning making. European Review of Social Psychology, 22, 164-214.

Phalet, K., \& Schonpflug, U. (2001). Intergenerational transmission of collectivism and achievement values in two acculturation contexts: The case of Turkish families in Germany and Turkish and Moroccan families in the Netherlands. Journal of Cross-Cultural Psychology, 32, 186-201.

Pike, A., Coldwell, J., \& Dunn, J. (2006). Family relationships in middle childhood. York: York Publishing Services/Joseph Rowntree Foundation.

Rogoff, B. (1990). Apprenticeship in thinking: Children's guided participation in culture. New York, NY: Oxford University Press.

Rothbaum, F., Pott, M., Azuma, H., Miyake, K., \& Weisz, J. (2000). Trade-offs in the study of culture and development: Theories, methods, and values. Child Development, 71, 1159-1161.

Rothbaum, F., \& Weisz, J. R. (1994). Parental caregiving and child externalizing behavior in nonclinical samples: A meta-analysis. Psychological Bulletin, 116, 55-74.

Rowe, D. C., Vazsonyi, A. T., \& Flannery, D. J. (1994). No more than skin deep: Ethnic and racial similarity in developmental process. Psychological Review, 101, 396-413.

Schwartz, S. H. (2006). A theory of cultural value orientations: Explication and applications. Comparative Sociology, 5, 137-182. 
Slobodskaya, H.R. (2015). Behavioral problems, effects of parenting and family structure on. International Encyclopedia of the Social \& Behavioral Sciences, 2, 470-476.

Stormshak, E. A., Bierman, K. L., McMahon, R. J., \& Lengua, L. J. (2000). Parenting practices and child disruptive behavior problems in early elementary school. Journal of Clinical Child Psychology, 29, 37-41.

Super, C. M., \& Harkness, S. (1986). The developmental niche: A conceptualization at the interface of child and culture. International Journal of Behavioral Development, 9, 545-569.

Tamis-LeMonda, C. S., Way, N., Hughes, D., Yoshikawa, H., Kalman, R. K., \& Niwa, E. Y. (2008). Parents' goals for children: The dynamic coexistence of individualism and collectivism in cultures and individuals. Social Development, 17, 183-209.

Vandenberg, R. J., \& Lance, C. E. (2000). A review and synthesis of the measurement invariance literature: Suggestions, practices, and recommendations for organizational research. Organizational Research Methods, 3, 4-70.

Worthman, C. M. (2010). The ecology of human development: Evolving models for cultural psychology. Journal of Cross-Cultural Psychology, 41, 546-562.

Yorukoglu, A. (1987). Child mental health. Ankara: Turkish Is Bank Cultural Publications. 